\title{
Yurii Semyonovich Genshaft. 28 September, 1935-April 1, 2009
}

PACS numbers: 01.60.+q

DOI: $10.1134 / \mathrm{S} 1069351309080011$

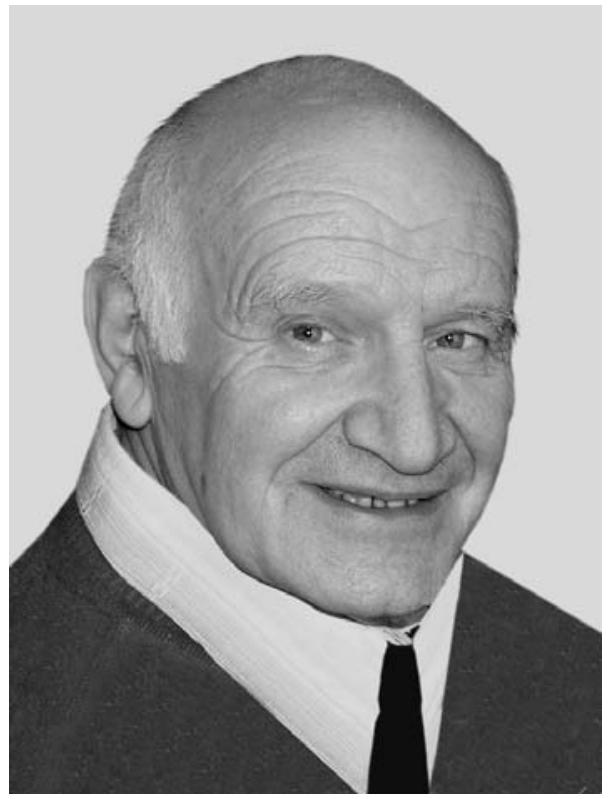

Yurii Semyonovich Genshaft, professor, doctor of physico-mathematical sciences, Honored Worker of Science of the Russian Federation, member of the editorial board of the journal "Physics of the Solid Earth", one of the major researchers in the field of experimental petrology and mineralogy, geophysics, tectonics, and general geology died on 1 April after a serious illness. He published approximately 400 scientific works, including 8 monographs, has 4 inventor's certificates in the field of obtaining synthetic diamonds.

Yurii Semyonovich was born in the city of Borisov in 1935 and moved to Moscow in 1943. After finishing school in 1953 with a golden medal, he graduated from the faculty of physics of the Moscow State University in 1958. He worked at the Institute of High-Pressure Physics (1959-1960), in the special sector of the IPE AS USSR (1961-1968), and headed a laboratory at the VNIIALMAZ (1968-1974). He began working at the IPE again since 1974 and until recently was the head of the laboratory of the physico-chemical dynamics of the technosphere. The sci- entific interests of Yu. S. Genshaft covered a wide spectrum of problems - technology and experimental investigations of physical and physico-chemical properties of different substances at high PT-parameters; mineralogy, petrology, and geochemistry; problems of abyssal and metamorphic rocks; natural diamond formation and synthesis of diamonds; and research on depth inclusions (including xenoliths) and mega-crystals as indicators of the material composition of the deep Earth's spheres. Field and laboratory researches led Yurii Seminovich to building substantial models of the Earth's interior.

Yurii Semyonovich was a true friend who always helped people (including people close to him as well as strangers) in any situation. He was always a leader in any group, a wise manager, and at the same time was a very simple communicator, always full of interesting ideas and scientific plans. Everybody who knew him will cherish the memory of this wonderful man and scientist for a long time keep. 